\title{
GESTÃO DA SUSTENTABILIDADE NO CULTIVO DA CANA-DE- AÇÚCAR: UM ESTUDO DE CASO NO NORDESTE DO BRASIL
}

\author{
Ana Regina Bezerra Ribeiro* \\ Fabiana Ferreira Silva** \\ Yasmim Silva Meireles**** \\ Felipe Lins de Melo***** \\ Rayanne de Paffer Rodrigues*****
}

RESUMO: Este trabalho teve como objetivo analisar práticas de gestão sustentáveis no cultivo da cana-de-açúcar. A questão-problema que motivou o estudo foi: que práticas gerenciais podem ser desenvolvidas visando à sustentabilidade no cultivo da cana-de-açúcar? Trata-se de uma pesquisa qualitativa compreendendo a análise de um caso na região Nordeste do Brasil. No estudo analisado, buscou-se: identificar práticas gerenciais que visam à melhoria no processo produtivo do açúcar; evidenciar os impactos ambientais e sociais provenientes do cultivo da cana-de-açúcar; e apresentar os ganhos obtidos com a mecanização do processo de colheita. Dentre os principais resultados, observou-se que houve uma evolução histórica na extração da cana e na busca por uma produção mais sustentável. A pesquisa ainda constatou que o investimento em sustentabilidade é alto, porém válido, possibilitando ganhos de produtividade, reconhecimento dos clientes e abertura a mercados internacionais.

PALAVRAS-CHAVE: Agroecossistemas; Meio ambiente; Práticas gerenciais; Processo produtivo.

\footnotetext{
Doutora em Engenharia de Produção, docente do Programa de Pós-Graduação em Administração e Desenvolvimento Rural (PADR) Universidade Federal Rural de Pernambuco (UFRPE), Brasil.

E-mail: anaregina.ribeiro@ufrpe.br

** Mestre em Administração, docente do Departamento de Administração da Universidade Federal Rural de Pernambuco (UFRPE), Brasill.

*** Bacharela em Administração pela Universidade Federal Rural de Pernambuco (UFRPE), Brasil.

**** Graduado em Gestão Pública e Especialista em Administração Pública (UNINTER), Brasil.

**** Bacharela em Administração pela Universidade Federal Rural de Pernambuco, pesquisadora do Núcleo de Pesquisa e Iniciação Científica (NUPIC-FAFIRE), Brasil.
} 


\title{
SUSTAINABILITY MANAGEMENT IN SUGAR CANE CULTURE: A CASE STUDY IN NORTHEASTERN BRAZIL
}

\begin{abstract}
Current paper analyzes practices of sustainable management in sugar cane culture. What management practices may be developed for the sustainability of sugar cane culture? Quality research analyzing a case in the northeastern region of Brazil identifies management practices for the improvement of the sugar cane production process; demonstrates the environmental and social impacts caused by sugar cane culture; provides gains obtained by mechanization of the harvest. Results show that there was a historical evolution in cane extraction and for a more sustainable production. Research has also registered that investing in sustainability is high, albeit valid, and presents gains in productivity, client acknowledgment and openness to international markets.
\end{abstract}

KEY WORDS: Agro-ecosystems; Environment; Management; Production process.

\section{INTRODUÇÃO}

Um levantamento da produção científica realizado no Portal de Periódicos da Coordenação de Aperfeiçoamento de Pessoal de Nível Superior (CAPES, 2015) apontou a existência de 124 pesquisas (teses, dissertações e artigos) contendo os descritores cana-de-açúcar, sustentabilidade e inovação, seja no título e/ou no assunto do trabalho. A busca foi realizada em outubro de 2015, sem recorte temporal, visando identificar todas as publicações que tivessem as palavras-chave (descritas em português e inglês) relacionadas à temática deste estudo, sendo identificada apenas uma pesquisa (DUARTE, 2013). Entretanto, a preocupação dessa pesquisa era apresentar uma proposta de procedimentos com base na avaliação da sustentabilidade e sua aplicação para o caso do etanol de cana-de-açúcar no Plano Decenal de Expansão de Energia.

Diante do exposto, destaca-se a necessidade de desenvolver estudos que investiguem os compromissos da gestão com a sustentabilidade no cultivo da cana-de-açúcar no que se refere à identificação de experiências exitosas e de problemas remanescentes nesse processo produtivo que existe há quase 500 anos no Brasil.

Dessa forma, a questão-problema que motivou esta pesquisa foi: como as práticas gerenciais podem impactar na sustentabilidade do cultivo da cana-de-açú- 
car? Outras inquietações permearam a pergunta principal da pesquisa por estarem diretamente relacionadas ao objeto em análise, a saber: quais práticas gerenciais são exitosas no cultivo sustentável da cana-de-açúcar? Como o cultivo da cana-de-açúcar afeta as dimensões social e ambiental? Que ganhos são obtidos com o processo de mecanização da colheita?

Partindo desse cenário, o objetivo geral deste artigo consistiu em analisar práticas de gestão sustentáveis no cultivo da cana-de-açúcar em uma unidade produtiva localizada na região Nordeste do Brasil. Para esta análise foram traçados os seguintes objetivos específicos: identificar ações de sustentabilidade que visam à melhoria no processo produtivo do açúcar e à qualidade de vida dos colaboradores; evidenciar os impactos ambientais e sociais provenientes do cultivo da cana-de-açúcar; apresentar os ganhos obtidos com a mecanização do processo de colheita.

De acordo com o portal Nova Cana (2015), a cana-de-açúcar é uma das principais culturas do mundo e representa uma importante fonte de mão de obra no meio rural de vários países. Apesar desta difusão mundial, cerca de $80 \%$ da produção do planeta está concentrada em dez países, sendo que a maior produção por hectare se localiza em terras brasileiras.

Além disso, é pertinente ressaltar que o Brasil é destaque mundial no uso de energias renováveis, as quais representam mais de $44 \%$ da matriz energética do país. O setor sucroenergético possui papel chave nesta participação, uma vez que somente os produtos da cana-de-açúcar são responsáveis por $15,7 \%$ de toda a oferta de energia do país (GOLDEMBERG, 2010).

O presente trabalho caracteriza-se como um ensaio teórico-empírico, de natureza qualitativa, organizado em seis seções: esta primeira contextualiza o tema, o problema, os objetivos e a relevância do estudo; a segunda seção traz as contribuições teóricas de diferentes autores abordando o cultivo da cana-de-açúcar, os impactos ambientais relacionados ao cultivo da cana-de-açúcar e os benefícios da colheita mecanizada da cana-de-açúcar; a terceira contempla os procedimentos metodológicos utilizados na pesquisa; a quarta seção apresenta os resultados do estudo; a quinta parte sistematiza as conclusões do trabalho; e, por fim, a sexta seção traz as referências bibliográficas que fundamentaram o estudo. 


\section{REFERENCIAL TEÓRICO}

Nesta seção são apresentados informações e conceitos de diferentes autores sobre os temas que fundamentaram a elaboração deste estudo, a saber: o cultivo da cana-de-açúcar; os impactos ambientais relacionados ao cultivo da cana-de-açúcar; e os benefícios da colheita mecanizada da cana-de-açúcar.

\subsection{BREVE HISTÓRICO DO CULTIVO DA CANA-DE-AÇÚCAR NO BRASIL}

O cultivo da cana-de-açúcar no Brasil é uma prática trazida pelas expedições europeias ao país com estágios de sucessos e insucessos nos ciclos de produção da cultura. O último momento de grande apogeu dos produtores de cana-de-açúcar ocorreu com a criação do Programa Nacional do Álcool - PNA, denominado Proálcool através do Decreto $\mathrm{n}^{0} 76.593$ (BRASIL, 1975), quando o Governo Federal defendeu uma solução alternativa para o consumo de combustíveis fósseis, o álcool (produzido através da cana-de-açúcar).

Nesse sentido, de acordo com Macedo e Nogueira (2004, p. 6), "A produção de cana aumentou de cerca de 120 para 240 milhões de toneladas entre 1975 e 1985, principalmente em função do PNA - Programa Nacional do Álcool”. Macedo (2007, p. 157) complementa que o Brasil é o maior produtor mundial de cana, açúcar e etanol. Ao mesmo tempo, esse autor afirma que "o uso de biocombustíveis representa uma das formas mais efetivas de reduzir as emissões líquidas de gases de efeito estufa".

De acordo com Corder (2012), o PNA foi criado em 1975 com a crise do petróleo, tendo o objetivo de diminuir a dependência da importação e do petróleo e de utilizar a capacidade inativa das usinas para instalar novas destilarias. Segundo o mesmo autor, foi realizado um controle de preço do álcool, na primeira fase do programa. Posteriormente, na segunda fase do Proálcool, foi incentivada a compra de carros a álcool, sendo reduzido o Imposto sobre Propriedade de Veículos Automotores (IPVA) e a taxa Rodoviária Única. Tais ações levaram a produção de carros a álcool atingir quase 95\% de total de carros produzidos no Brasil em 1985.

Por outro lado, ao final dos anos 80 , aconteceu um desabastecimento por excesso de venda dos carros movidos a álcool, o que obrigou o Brasil importar me- 
tanol. Logo após a esse momento, o então Presidente da República, Fernando Collor de Mello, liberou o mercado ${ }^{1}$, diminuindo ainda mais o consumo do álcool. Mesmo diminuindo o consumo do álcool como combustível, o Proálcool ajudou na transformação do álcool como uma opção de negócio para o produtor de cana-de-açúcar, ampliando sua área de cultivo e o número de destilarias (FISCHER, 1983 apud CORDER, 2012).

Hoje, a cana continua sendo cultivada no país, tanto para a produção de açúcar quanto para a produção de álcool. Nesse sentido, o tema sobre o cultivo da cana-de-açúcar está cada vez mais relevante, pois cresce a busca pela responsabilidade socioambiental, sendo necessária uma ampla discussão sobre o cultivo e colheita da cana-de-açúcar.

\subsection{IMPACTOS AMBIENTAIS RELACIONADOS AO CULTIVO DA CANA-DE-AÇÚCAR}

Entre os vários problemas que o cultivo da cana-de-açúcar pode causar, um dos mais discutidos é a poluição atmosférica causada pela prática da queima da cana antes da colheita manual.

Segundo Cançado et al. (2006), a queima de biomassa está entre as fontes naturais de poluição do ar. Para o autor, essa queima é utilizada desde a pré-história e tem sido uma das importantes fontes de poluição atmosférica que, após a revolução industrial, passou a sofrer também com a queima de combustíveis fósseis.

Estudos que relacionam a poluição atmosférica a doenças, principalmente respiratórias, têm sido motivadores na busca por mudanças no processo de colheita da cana (FRANCO, 1992; ARBEX et al., 2004; ALVES, 2006; CANÇADO et al., 2006; TRAPIDO-LURIE, 2014). É importante ressaltar que várias empresas têm buscado uma melhoria nos seus processos para alcançar melhores níveis nos indicadores socioambientais, porém encontram um desafio na utilização da queimada.

De acordo com Cançado et al. (2006), estudos epidemiológicos indicam uma relação consistente entre a queima de biomassa e o desenvolvimento de doença pulmonar crônica em adultos, como: bronquiectasias, fibrose pulmonar e infecções respiratórias em crianças.

\footnotetext{
1 Política econômica que possibilitou a abertura comercial para a importação de produtos com menos impostos.
} 
Isso alerta para o risco sofrido por trabalhadores rurais responsáveis pela colheita da cana-de-açúcar ao serem expostos à poluição atmosférica causada pela queima da biomassa, uma prática comum no processo de colheita.

Segundo o Serviço Pastoral do Migrante de Guariba (SP), entre as safras 2004/2005 e 2006/2007 morreram 14 cortadores de cana na região canavieira de São Paulo. Nos atestados de óbitos consta apenas que os trabalhadores morreram ou por parada cardíaca ou insuficiência respiratória ou acidente vascular cerebral (ALVES, 2006, p. 2).

Para Arbex et al. (2004), a cana-de-açúcar traz muitos malefícios causados pela poluição da queima de biomassa, prática considerada comum no interior do Brasil. Os efeitos maléficos da queima de biomassa não atingem apenas os seres humanos, que têm contato direto com as partículas poluentes, mas também o próprio meio ambiente, que é afetado direta e indiretamente pela poluição.

A fumaça decorrente da queima de biomassa em ambientes abertos produz efeitos adversos indiretos sobre a saúde, como a redução da fotossíntese, o que provoca diminuição das culturas agrícolas, ou o bloqueio dos raios ultravioletas A e B, o que provoca um aumento de microorganismos patogênicos no ar e na água, além do aumento de larvas de mosquitos transmissores de doenças (ARBEX et al., 2004, p. 166).

A maior parte das queimadas retratadas nos estudos sobre poluição atmosférica diz respeito a episódios fortuitos. Porém, a queima da cana-de-açúcar é um episódio singular porque ocorre de forma programada. Consequentemente, as regiões onde as queimadas ocorrem ficam expostas ao material particulado negro, denominado "fuligem da cana", por aproximadamente seis meses ao ano (ARBEX et al., 2004).

O Laboratório de Poluição Atmosférica Experimental (LPAE) do Departamento de Patologia da Faculdade de Medicina da Universidade de São Paulo estudou os efeitos causados pela queima de biomassa em duas regiões de São Paulo: Piracicaba e Araraquara, que estão entre os maiores produtores de cana-de-açúcar do planeta (ARBEX et al., 2004). Para esses autores, o interesse do ponto de vista médico pelo problema caracteriza-se pelo fato de que pacientes com doenças respiratórias crônicas demonstram agravamento dos sintomas apresentados no período de quei- 
mada da cana. Ao mesmo tempo, há elevação dos casos de pacientes saudáveis que apresentam determinados sintomas, como irritação nas vias aéreas superiores, ardor no nariz e na garganta nesta época do ano.

Franco (1992) listou algumas considerações a respeito da relação entre a queima da cana-de-açúcar e agravos à saúde:

- durante a época das queimadas dos canaviais há uma piora na qualidade do ar na região;

- a queimada dos canaviais não é o único fator de agravamento da qualidade do ar, mas em consequência da extensão da área plantada e da duração das queimadas, final de abril a início de novembro, as descargas de gases e de outros poluentes na atmosfera da região ganham um significado importante e não podem ser menosprezadas;

- a população de risco, que tem sua qualidade de vida e de saúde agravada em condições atmosféricas adversas, é bastante significativa;

- a maioria das pessoas que compõe a população de risco demanda um número muito maior de consultas, atendimentos ambulatoriais, medicação e internações. Isso onera não só os serviços médicos, mas a economia das famílias.

As mudanças físicas e biológicas sofridas pelo ambiente, provenientes da ação humana, resultam em um grande prejuízo para a saúde. A extensão dessas mudanças não está totalmente estabelecida. Trapido-Lurie (2014, p. 1) apresenta um estudo multidisciplinar realizado por especialistas do Reino Unido, EUA, Índia, Brasil, África do Sul e Austrália acerca dos impactos ambientais. A autora comenta sobre um novo projeto centrado na agricultura, como base do crescimento econômico, sendo uma importante fonte de subsistência em três países (Brasil, Índia e África do Sul) e afirma que "esses países estão sob pressão para melhorar a eficiência dos recursos e aumentar a capacidade de resistência à futura incerteza climática”.

Apesar da importância econômica e de subsistência da agricultura para o Brasil, é necessário melhorar a eficiência na utilização dos recursos naturais, bem como reconhecer a influência das técnicas antropogênicas sob a futura incerteza climática.

De acordo com Tôsto e Pereira (2012, p. 3): 
O rápido desenvolvimento do setor sucroalcooleiro pode acarretar impactos ambientais negativos e externalidades, entre elas: o uso, ocupação e degradação de ecossistemas florestais, principalmente das Áreas de Preservação Permanente (APPs) e de Reserva Legal (RL); emissões de gases de efeito estufa decorrentes das queimadas; assoreamento dos corpos d'água; e contaminação de cursos d'água e do lençol freático.

Arbex et al. (2004) conclui que a contínua modificação dos sistemas ecológicos que sustentam a vida humana poderá representar uma ameaça à saúde de forma global no futuro.

\subsection{PROCESSO DE MECANIZAÇÃO NA COLHEITA DE CANA-DE-AÇÚCAR}

Os gestores de uma organização do ramo sucroalcooleiro precisam tomar decisões estratégicas quanto ao processo produtivo da cana-de-açúcar. Neste sentido, a análise de dois tipos de colheita de cana, que são utilizados no Brasil, visa contrapor os processos de modo a facilitar a compreensão do processo decisório desses gestores e analisar o compromisso com a sustentabilidade.

Souza et al. (2005) advertem que o tipo de colheita da cana-de-açúcar pode acarretar alterações na produção e longevidade da cultura, além de influenciar o solo, o meio ambiente e a saúde pública. Tais autores ressaltam a importância do Decreto de Lei Estadual 47.700, de 11 de março de 2003, o qual determina prazos para a eliminação gradativa do emprego do fogo para despalha da cana-de-açúcar nos canaviais paulistas.

Em contrapartida à queimada, esses autores falam sobre a crescente colheita mecanizada no Brasil e explicam que

no sistema de colheita mecanizada sem queima, as folhas, bainhas, ponteiro, além de quantidade variável de pedaços de colmo são cortados, triturados e lançados sobre a superfície do solo, formando uma cobertura de resíduo vegetal (mulch) denominada palha ou palhada (SOUZA et al., 2005, p. 271).

Demonstrando a real possibilidade de implantação de um sistema eficiente e socialmente responsável de colheita, Shaochun et al. (2014) afirmam que o sistema 
de colheita manual era utilizado antes da introdução do sistema mecanizado e recorda que o sistema manual ainda é utilizado em grande escala em países subdesenvolvidos e em desenvolvimento.

A preocupação com a preservação ambiental e a saúde pública parece sempre presente quando se trata da criação e utilização das técnicas de colheita mecanizada.

Souza et al. (2005) apontam a eliminação da queimada como princípio finalístico do desenvolvimento do sistema de colheita mecanizada. Esse autor mostra um caso bem sucedido de colheita mecanizada em experimento realizado em Jaboticabal (SP). O experimento foi realizado em área de topografia plana, diferente do que é encontrado no Estado de Pernambuco, citado por Moraes (2007) como um dos grandes produtores de cana do país. Esse é um dos impasses que mantém viva a prática secular da queimada da cana-de-açúcar antes da realização da colheita.

Apesar de possíveis dificuldades de implementação, a mecanização é apontada por alguns produtores como a opção mais adequada para as atuais demandas do setor, como a diminuição de mão de obra e o compromisso com a responsabilidade socioambiental. "A mecanização total ou parcial se apresenta atualmente como a única opção para a colheita da cana, tanto do ponto de vista ergonômico quanto econômico e, principalmente, do ponto de vista legal e ambiental" (BRAUNBECK; MAGALHÃES, 2010). É pertinente salientar que no aspecto ergonômico trata-se de considerar a adequação de máquinas e equipamentos à atividade realizada pelos colaboradores a fim de minimizar problemas ocupacionais.

Resultados semelhantes foram alcançados em um estudo realizado por Tôsto e Pereira (2012), que compararam o índice de sustentabilidade ambiental nos dois sistemas de extração da cana-de-açúcar: a cana queimada e a cana mecanizada, utilizando a análise multicritério de apoio à decisão construtivista. A conclusão do trabalho aponta a extração da cana pela queimada como uma condição de manejo inadequada, com consequências ambientais, econômicas e sociais, apresentando um baixo valor de sustentabilidade ambiental (41,8\%); por outro lado, utilizando-se dos mesmos critérios de análise, foi encontrado o índice de sustentabilidade ambiental de $65 \%$ para a colheita mecanizada de cana. Também foi observado que houve uma maior conservação do solo, utilização mais adequada de produtos fitossanitários e 
fertilizantes, além de maior respeito à legislação ambiental. Segundo Tôsto e Pereira (2012, p. 8), "o índice de sustentabilidade ambiental da cana-de-açúcar mecanizada foi aproximadamente $50 \%$ superior ao encontrado para a cana-de-açúcar queimada".

Segundo Braunbeck e Magalhães (2010), o princípio de colheita mecanizada utilizado hoje no Brasil surgiu na Austrália na década de 1950. Mesmo tendo sido realizada pela primeira vez há mais de meio século, a colheita mecanizada enfrenta várias dificuldades de implementação para ser incorporada ao cultivo da cana como uma prática comum, pois exige altos investimentos financeiros em pesquisa e desenvolvimento e compra de novas tecnologias, além do custo social, demissão de grande número de operários.

Por outro lado, Salomão (2009) relata a experiência de uma usina no Sudeste do Brasil que produzia 95\% do açúcar orgânico do país e atendia 30\% do mercado global, sendo a maior produtora e maior exportadora de açúcar orgânico do mundo em 2009 (67 países recebem o açúcar desta empresa). A gestão desta usina investiu no sistema de monocultura em larga escala, sendo $100 \%$ mecanizada. A preocupação da referida usina se dá, também, com a diversidade de animais, tendo mais de 340 espécies em seus canaviais, bem como o combate ao aquecimento global fez a usina banir as queimadas e os fertilizantes químicos, grandes emissores de gás carbônico.

Nesse sentido, a empresa não utiliza herbicidas, pesticidas, nenhum tipo de fertilizantes, nem adubos orgânicos de origem animal. Para tanto, a fertilização do solo é realizada por meio de uma associação entre as folhas da cana que são espalhadas sobre a cultura para proteger e nutrir o solo (SALOMÃO, 2009).

O mesmo autor enfatiza o compromisso da gestão da usina estudada com a sustentabilidade fazendo com que fosse possível a concretização de um sonho que parecia impossível: atualmente, a usina é considerada um caso bem sucedido de empreendedorismo agrícola. Essa empresa chega a ser $23 \%$ mais produtiva que as usinas tradicionais no cultivo da cana.

Descobrindo que o solo precisava de mais cuidados, essa usina do Sudeste do Brasil passou a utilizar, a cada safra, cerca de 15 mil toneladas de folhas da cana-de-açúcar para formar uma camada de $3 \mathrm{~cm}$ sobre o solo em 14 mil hectares, protegendo-o do sol e gerando alta fertilidade. A melhoria do processo produtivo se deu, também, pela substituição da colheita manual pela mecanizada, não havendo mais 
o processo de queimada, que foi substituído por um novo modelo de colheitadeira. Foi necessária uma mudança no desenho do canavial que passou a ter corredores mais amplos em forma de ondas. Com a colheita mecanizada foi necessário fazer investimentos em pesquisas para desenvolver um tipo de vespa modificada que se alimentasse da broca (larva que causa danos à cana), a fim de diminuir os insetos que surgiram em decorrência da extinção das queimadas.

De acordo com Salomão (2009), os investimentos na cadeia produtiva de açúcar orgânico trouxeram muitos ganhos financeiros para essa usina, incluindo certificações internacionais que geraram uma nova motivação para os empreendedores e criaram um novo conceito de negócio mais sustentável e integrado à natureza.

Benefícios semelhantes foram observados na usina analisada provenientes da adoção de práticas gerenciais sustentáveis. Nesta pesquisa, tomando por base Claro, Claro e Amâncio (2008), essas práticas sustentáveis constituem ações gerenciais voltadas à preservação de impactos ambientais. Para tanto, esses autores apresentam oito tipos de práticas gerenciais sustentáveis que devem ser realizadas pelas organizações: prevenção da poluição da água; prevenção da poluição do solo; prevenção da poluição do ar; diminuição/extinção do número de acidentes ambientais decorrentes das atividades da empresa; separação e reciclagem de resíduos; tratamento de materiais perigosos para evitar acidentes; utilização de fontes alternativas de energia; e investimento em equipamentos que utilizam menos energia.

Nesse sentido, é pertinente salientar que práticas gerenciais sustentáveis demandam alto grau de comprometimento das organizações para que se tornem ambientalmente responsáveis com todos os seus stakebolders (colaboradores, clientes, fornecedores, concorrentes, governo, comunidade, dentre outros).

Após serem apresentados os aportes teóricos que fundamentaram a pesquisa, na próxima seção constam os procedimentos metodológicos que conduziram o alcance dos objetivos propostos.

\section{MATERIAL E MÉTODOS}

Esta pesquisa caracteriza-se como um estudo de natureza qualitativa cuja preocupação fundamental é compreender o fenômeno e seus possíveis impactos na realidade vivenciada (MERRIAM, 2007). 
Quanto aos fins, a investigação classifica-se como exploratória, descritiva e aplicada; quanto aos meios, trata-se de uma pesquisa de campo e bibliográfica (VERGARA, 2013).

O campo analisado compreendeu as práticas gerenciais de uma usina de cana-de-açúcar situada no Estado de Pernambuco, Nordeste do Brasil, cuja identidade foi preservada a fim de manter o sigilo das informações gerenciais. Acerca da unidade produtiva em análise, é pertinente salientar que a usina é proprietária das terras onde cultiva a cana-de-açúcar e nos últimos anos vem investindo em pesquisa sobre práticas gerenciais sustentáveis.

A unidade produtiva analisada caracteriza-se como uma usina tradicional que produz etanol, energia elétrica e açúcar, sendo que este último compreende $98 \%$ da sua produção.

Os dados foram coletados em fontes primárias no período de março a junho de 2016, mediante a realização de entrevistas semiestruturadas e aprofundadas com dois gestores da usina: o diretor geral e um gestor na área de produção. No que se refere ao tratamento das informações coletadas na entrevista, realizou-se a análise de conteúdo proposta por Bardin (2009), cuja modalidade temática consistiu em descobrir os núcleos de sentido que permearam a comunicação. Essa técnica possibilitou verificar a existência de determinados temas que denotam estruturas de relevância, valores de referência e modelos de comportamentos presentes ou subjacentes ao discurso. Operacionalmente, esse método contemplou: a pré-análise (leitura flutuante das informações da entrevista, constituição do corpus, formulação e reformulação dos pressupostos da pesquisa); a exploração do material (operação classificatória visando alcançar o núcleo de compreensão do texto mediante categorização); e o tratamento dos resultados obtidos para interpretação (realização de inferências fundamentadas no quadro teórico do estudo).

Dessa forma, organizou-se as informações da entrevista em quatro categorias: compromisso da gestão com a sustentabilidade; melhorias no processo; avanços tecnológicos; e problemas remanescentes. A próxima seção traz a sistematização e discussão dos resultados conforme o percurso metodológico apresentado. 


\section{RESULTADO E DISCUSSÃO}

Esta seção sistematiza os principais resultados da pesquisa tendo como base os objetivos propostos. Observou-se que o processo produtivo da indústria sofreu alterações provenientes de avanços tecnológicos e descobertas científicas, como a mecanização da colheita. Porém, a presença do fator humano no plantio e na colheita da cana continua sendo uma realidade na região. Nesta usina, são mais de dois mil cortadores de cana que trabalham durante o período de safra.

Foi constatado que a mecanização da colheita enfrenta dificuldades para ser implantada devido ao relevo da região e ao investimento necessário para a realização desta modernização. Atualmente, apenas $10 \%$ da colheita é mecanizada apesar de $40 \%$ de o terreno ser mecanizável. Diante disso, ainda é utilizada a queimada da cana para que seja realizada a colheita pelos cortadores, técnica que gera prejuízos ambientais e expõe os trabalhadores a possíveis problemas de saúde. De acordo com os entrevistados, a empresa também perde na eficiência da realização do processo produtivo, pois a queimada gera fissuras na casca da cana, que fica exposta à atuação de micro-organismos que geram a perda da quantidade de sacarose da cana. Com a qualidade afetada, o açúcar tende a não atender às especificações dos clientes que são grandes indústrias de refrigerante e bebidas alcoólicas.

Com a finalidade de melhorar o processo produtivo, a usina investe na gestão de pessoas, buscando oferecer condições dignas de trabalho aos cortadores, disponibilizando a eles cuidados médicos e instalações que propiciam qualidade de vida no trabalho.

Entretanto, enquanto for utilizado o método tradicional de corte de cana, o impacto causado pela exposição a essas partículas continua. A mecanização da colheita dispensaria a queimada e evitaria a exposição de um numeroso contingente de trabalhadores e da população em geral aos efeitos maléficos citados. Por outro lado, na visão dos gestores da empresa, a mecanização traz algumas desvantagens: além do possível aumento de demissões, existe uma perda de cerca de $10 \%$ de toda a colheita quando feita de forma mecanizada.

Diante do exposto, várias atitudes foram tomadas pelo grupo visando à construção de uma cultura de responsabilidade socioambiental. Nas estradas que levam à usina é facilmente identificável a presença de reservas de vegetação nativa 
em meio à área de cana plantada, também existem projetos de reflorestamento que conscientizam crianças de escolas da região e a utilização do refugo da produção em novos processos, como o que resulta na produção de energia. Porém, ainda é remanescente o problema social referente à saúde dos dois mil cortadores que trabalham durante seis meses em condições pouco adequadas.

No que se refere aos objetivos do estudo, o Quadro 1 apresenta uma descrição das práticas realizadas no cultivo da cana-de-açúcar na usina analisada possibilitando verificar as melhorias efetivadas no processo produtivo do açúcar, os avanços tecnológicos e os problemas remanescentes.

Quadro 1. Análise da usina quanto à sustentabilidade

\begin{tabular}{|l|l|}
\hline Itens Avaliados & Práticas Realizadas no Cultivo da Cana-de-Açúcar \\
\hline $\begin{array}{l}\text { Compromisso da } \\
\text { gestão com a susten- } \\
\text { tabilidade }\end{array}$ & $\begin{array}{l}\text { Presença de reservas de vegetação nativa em meio à área de cana plantada. } \\
\text { Existem projetos de reflorestamento envolvendo crianças de escolas da } \\
\text { região e a utilização do refugo da produção (bagaço da cana-de-açúcar) } \\
\text { em novos processos. }\end{array}$ \\
\hline $\begin{array}{l}\text { Melhorias no pro- } \\
\text { cesso }\end{array}$ & $10 \%$ da colheita são mecanizados e produção de energia. \\
\hline Avanços tecnológicos & $\begin{array}{l}\text { Compromisso com a inovação incremental do processo: apenas } 10 \% \text { da } \\
\text { colheita são mecanizados. }\end{array}$ \\
\hline Problemas & $\begin{array}{l}\text { A mecanização da colheita enfrenta dificuldades para ser implantada, de- } \\
\text { vido ao relevo da região e ao investimento necessário para a realização } \\
\text { desta modernização. }\end{array}$ \\
\hline
\end{tabular}

Fonte: Dados da pesquisa (2015).

Considerando as categorias elencadas no Quadro 1, no que se refere ao compromisso da gestão com a sustentabilidade, observou-se na pesquisa que o grupo agroindustrial promove uma gestão com o foco no desenvolvimento responsável, com políticas que envolvem questões sociais, econômicas e ambientais, ultrapassando os compromissos legais. São diversos programas e ações oferecidas pensando na garantia da qualidade de vida dos colaboradores empregados na instituição, no desenvolvimento da região e na preservação do meio ambiente. A organização mantém uma reserva de mata atlântica preservada, uma das maiores do Nordeste. A área preservada está em constante ampliação, através de programas de reflorestamento, que visa à recuperação de matas ciliares, por meio de práticas de voluntariado, mobi- 
lizando alunos, colaboradores e sociedade civil. Ao mesmo tempo, a unidade produtiva mantém um controle para proteção e eliminação de possíveis focos de incêndio com torres de observação, instaladas estrategicamente e com carros-pipa, bem como mantém um programa de gestão de resíduos, obedecendo às legislações vigentes. Também foi observado que a organização utiliza o refugo da produção (bagaço da cana-de-açúcar) na produção de energia, aproveitando quase todo insumo.

No que se refere às melhorias no processo, a organização possui Sistema de Gestão de Qualidade em Segurança dos Alimentos (ISO 22000:2006), juntamente com o programa de pré-requisitos (ISOTS 22002), que compõem o Food Safety System Certification 22000 (FSSC 22000), garantindo a segurança e a excelência dos produtos fabricados.

Em relação aos avanços tecnológicos, a organização tem como um dos seus objetivos evoluir tecnologicamente, melhorando o desempenho dos processos, respeitando o meio ambiente e atendendo à legislação vigente. Apesar de todo o investimento empregado na inovação dos seus processos, apenas $10 \%$ da colheita é mecanizada.

Por fim, quantos aos problemas encontrados, a administração enfrenta a adversidade do relevo acidentado. Sobre esse aspecto, foi informado que seria muito dispendioso investir no desenvolvimento de máquina ou em terraplanagem do terreno, podendo inviabilizar o negócio.

Tomando por base a fundamentação teórica e os dados da pesquisa de campo, fica evidente que é indispensável o comprometimento da alta administração da empresa na implementação de uma produção sustentável. Isso exige um grande investimento financeiro na mudança do processo operacional e na aquisição de novas tecnologias, além da necessidade de um planejamento em longo prazo que também auxilie na superação de possíveis resistências dos empregados.

O caso da usina analisada mostra uma preocupação da administração da organização na preservação da vegetação nativa em meio à área de cana plantada, porém ainda conta com uma grande presença do fator humano no plantio e na colheita do produto. A organização tenta minimizar os problemas ambientais causados com projetos de reflorestamento envolvendo crianças de escolas da região nessa conscientização, bem como utiliza o refugo da produção em novos processos, resultando na produção de energia. 
Ainda é pertinente salientar que essa usina fornece açúcar para indústrias que precisam de um produto com determinada especificação, sem tanta obrigação de o açúcar ser orgânico, atende ao mercado atual. De acordo com os gestores da usina analisada, no futuro há possibilidade de realizar um investimento na fabricação do açúcar orgânico possibilitando a entrada em mercados internacionais, nos quais o público-alvo valoriza produtos naturais, independente do seu preço.

\section{CONSIDERAÇÕES FINAIS}

A colheita de cana-de-açúcar de forma manual necessita da queima de biomassa, podendo causar nos trabalhadores doenças respiratórias, paradas cardíacas ou acidentes vasculares cerebrais provenientes da exposição à poluição atmosférica. O meio ambiente também sofre com a queimada, pois esta gera a produção de gases tóxicos, material particulado, gases de efeito estufa no planeta, além da morte de animais de várias espécies.

Em contrapartida à queimada, ficou claro na pesquisa que no sistema de colheita mecanizada (sem queima), muitas vezes há uma perda de 10\% da colheita, pois inexiste uma separação de folhas e outros detritos.

Percebeu-se uma evolução histórica na extração da cana e na busca por uma produção mais sustentável por parte dos gestores. Porém, há um caminho longo a percorrer pela usina estudada, pois o investimento feito na mudança da forma de colheita de cana necessita de um bom investimento financeiro em pesquisa e desenvolvimento. Faz-se necessário, ainda, uma mudança cultural nos consumidores e nas empresas clientes para que passem a valorizar a qualidade do processo, não se limitando ao preço.

Quanto à sustentabilidade no processo de colheita de cana-de-açúcar, ficou constatado que os gestores buscam melhorias no processo, adotando novas práticas operacionais e investindo em certificações ambientais para aumentar a sustentabilidade da empresa. Na usina analisada, as inovações foram incrementais: a empresa mecanizou $10 \%$ do processo e pretende mecanizar mais $30 \%$ de toda a colheita. Segundo depoimentos dos gestores, a empresa está investindo em pesquisa, mas o relevo dificulta a mecanização do processo. 
Ficou claro que a colheita mecanizada traz melhorias na sustentabilidade das usinas, porém o processo de implementação de novas tecnologias necessita de investimentos financeiros em pesquisa e implementação de novas tecnologias. É importante que a alta administração mantenha a sua visão empreendedora para ganhar em produtividade, fruto de um processo de inovação radical.

Reitera-se que o investimento em práticas sustentáveis é válido e traz benefícios a longo prazo, inclusive abertura a mercados internacionais. Não se trata de um caminho fácil e, como todo investimento, depende do compromisso da gestão com a sustentabilidade.

Como sugestão para outros estudos, recomenda-se analisar a influência da cultura organizacional no processo de mecanização da colheita da cana, podendo também pesquisar sobre o impacto social causado com a mecanização da colheita. Outro tema de pesquisa seria verificar o desenvolvimento de novas tecnologias para o processo de produção de açúcar, de etanol e de energia a partir da cana-de-açúcar.

\section{REFERÊNCIAS}

ALVES, F. Por que morrem os cortadores de cana. Saúde e Sociedade, v. 15, n. 3, p. 90-98, 2006. Disponível em: < http://goo.gl/2haLPT> Acesso em: 04 fev. 2015.

ARBEX, M. A.; CANÇADO, J. E.; PEREIRA, L. A.; BRAGA, A.; SALDIVA, P. H. Queima de biomassa e efeitos sobre a saúde. J braspneumol, v. 30, n. 2, p. 158-75, 2004. Disponível em: < http://goo.gl/Q553qF> . Acesso em: 04 jan. 2015.

BARDIN, L. Análise de Conteúdo. Lisboa: Edições 70, 2009.

BRASIL. Decreto $\mathrm{n}^{\mathrm{O}} \mathbf{7 6 . 5 9 3}$, de 14 de novembro de 1975. Institui o Programa Nacional do Álcool e dá outras Providências. Diário Oficial da União, Brasília, 14 nov. 1975. Disponível em: < http://goo.gl/sJHv3j> . Acesso em: 14 fev. 2016.

BRAUNBECK, O. A.; MAGALHÃES, P. S. G. Colheita de cana-de-açúcar com auxílio mecânico. 2010. Disponível em: https://goo.gl/pPcS9s. Acesso em: 05 mar. 2015. 
CANÇADO, J. E.; BRAGA, A.; PEREIRA, L. A.; ARBEX, M. A.; SALDIVA, P. H.; SANTOS, U. Repercussões clínicas da exposição à poluição atmosférica. J braspneumol, v. 32, n. Supl. 1, p. S5-S11, 2006. Disponível em: http://goo.gl/j4yTZ7. Acesso em: 04 jan. 2015.

CAPES. Coordenação de Aperfeiçoamento de Pessoal de Nível Superior. Portal de Periódicos. Disponível em: http://www.periodicoscapes.gov.br. Acesso em: 27 out. 2015.

CLARO, P. B.; CLARO, D. P.; AMÂNCIO, R. Entendendo o conceito de sustentabilidade nas organizações. Revista de Administração, v. 43, n. 4, p. 289-300, 2008.

CORDER, L. M. Análise da dinâmica da produção de produtos agrícolas usados como matéria-prima para biocombustíveis e para alimentos na década de 2000 em países selecionados. 2012. 269 f. Dissertação (Mestrado em Economia Aplicada) - Escola Superior de Agricultura Luiz de Queiroz, Piracicaba, 2012. Disponível em: http://goo.gl/8U6Qek. Acesso em: 17 fev. 2016.

DUARTE, C. G. Planejamento e sustentabilidade: uma proposta de procedimentos com base na avaliação de sustentabilidade e sua aplicação para o caso do etanol de cana-de-açúcar no Plano Decenal de Expansão de Energia. 2013. 303 f. Tese (Doutorado em Ciências da Engenharia Ambiental) - Universidade de São Paulo, São Carlos. 2013. Disponível em: http://goo.gl/biF3Cu. Acesso em: 29 out. 2015.

FRANCO, A. R. Aspectos epidemiológicos da queimada de canaviais na região de Ribeirão Preto. Ribeirão Preto: Centro de Estudos Brasileiros, 1992.

GOLDEMBERG, J. Etanol e bioeletricidade: a cana-de-açúcar no futuro da matriz energética. SOUSA, E. L.; MACEDO, I. C. São Paulo: Luc Projetos de Comunicação, 2010.

MACEDO, I. C. Situação atual e perspectivas do etanol. Estudos avançados, v. 21, n. 59, p. 157-165, 2007. Disponível em: http://goo.gl/6T0cq8. Acesso em: 17 fev. 2016.

MACEDO, I. C.; NOGUEIRA, L. A. H. Avaliação da expansão da produção de etanol no Brasil. Centro de Gestão e Estudos Estratégicos. July, 2004. Disponível em: http:// goo.gl/fB5kA1. Acesso em: 17 fev. 2016.

MERRIAM, S. B. Qualitative research and case study apllications in education. 2. nd. San Francisco: Jossey-Bass, 2007. 
MORAES, M. A. F. D. Indicadores do mercado de trabalho do sistema agroindustrial da cana-de-açúcar do Brasil no período 1992-2005. Estudos Econômicos (São Paulo), v. 37, n. 4, p. 875-902, 2007. Disponível em: http:/goo.gl/xrFMMR. Acesso em: 05 mar. 2015.

NOVA CANA. A produção de cana-de-açúcar no Brasil e no Mundo. Disponível em: http://goo.gl/QZ1qLk. Acesso em: 04 jan. 2015.

SALOMÃO, A. Natureza inovadora. Época Negócios, v. 30, p. 86-101, 2009. Disponível em: http://goo.gl/fLfn8l. Acesso em: 06 mar. 2015.

SHAOCHUN, M. et al. Sugarcane Harvester Technology: a critical overview. Applied Engineering in Agriculture, v. 30, n. 5, p. 727-739, 2014. Disponível em: http:// goo.gl/W9yjre. Acesso em: 07 mar. 2015.

SOUZA, Z. M.; PRADO, R. M.; PAIXÃO, A. C. S.; CESARIN, L. G. Sistemas de colheita e manejo da palhada de cana-de-açúcar. Pesq. agropec. bras., Brasília, v. 40, n. 3, p. 271-278, 2005. Disponível em: http://goo.gl/7xwAbH. Acesso em: 17 fev. 2016.

TÔSTO, S. G.; PEREIRA, L. C. Avaliação da cultura da cana-de-açúcar com foco na sustentabilidade ambiental. Seminário Internacional Nova Territorialidades e Desenvolvimento Sustentável, Recife: GRAPP, 2012. Disponível em: http://goo.gl/ QV0bct. Acesso em: 12 fev. 2016.

TRAPIDO-LURIE, B. Researcher studies impact of increased sugarcane production. 2014.

VERGARA, S. C. Projetos e Relatórios de Pesquisa em Administração. 14. ed. São Paulo: Atlas, 2013.

Recebido em: 21/02/2016 Aceito em: 05/11/2017 